Research Article

Human and Medical Genetics

\title{
Association between SNP rs527616 in IncRNA AQP4-AS1 and susceptibility to breast cancer in a southern Brazilian population
}

\author{
Rafael D. Marchi ${ }^{1}$ (1), Carolina Mathias ${ }^{1}$, Gabriel A. K. Reiter ${ }^{1}$, Rubens Silveira de Lima², \\ Flávia Kuroda ${ }^{2}$, Cícero de Andrade Urban ${ }^{2}$, Ricardo. L. R. de Souza ${ }^{1}$ (D), Daniela F. Gradia ${ }^{1}$ (D), \\ Enilze M. S. F. Ribeiro ${ }^{1}$ (D), Iglenir J. Cavalli ${ }^{1}$ and Jaqueline Carvalho de Oliveira ${ }^{1}$ (D) \\ ${ }^{1}$ Universidade Federal do Paraná, Departamento de Genética, Curitiba, PR, Brazil. \\ ${ }^{2}$ Hospital Nossa Senhora das Graças, Centro de Doenças da Mama, Curitiba, PR, Brazil.
}

\begin{abstract}
Breast cancer $(\mathrm{BC})$ is the leading cause of death by this disease in women worldwide. Among the factors involved in tumorigenesis, long non-coding RNAs (IncRNAs) and their differential expression have been associated. Differences in gene expression may be triggered by variations in DNA sequence, including single nucleotide polymorphisms (SNPs). In the present study, we analyzed the rs527616 (C>G), located in the IncRNA AQP4-AS1, using PCR-SSP in 306 BC patients and 312 controls, from a Brazilian population. In the BC group, the frequency found for $C G$ heterozygotes was above the expected and the overdominant model is the best one to explain our results (OR: 1.70, IC 95\%: 1.23-2.34, $\mathrm{P}<0.001)$. Furthermore, the SNP were associated with age at $\mathrm{BC}$ diagnosis and the risk genotype more frequent in the older age group. According to TCGA data, AQP4-AS1 is down-regulated in BC tissue, and the overexpression is associated with better prognoses, including Luminal A, HER2-, stage 1 of disease and smaller tumor. In conclusion, the CG genotype is associated with increased susceptibility in the southern Brazilian population. This SNP is mapped in the IncRNA AQP4-AS1, showing differential expression in BC samples. Based on these results, we emphasize the potential of the role of AQP4-AS1 in cancer.
\end{abstract}

Keywords: rs527616, IncRNA AQP4-AS1, breast cancer, case-control study, Brazilian population.

Received: June 27, 2020; Accepted: January 18, 2021.

\section{Introduction}

Breast cancer is the most commonly diagnosed neoplasm in women worldwide (Bray et al., 2018). In Brazil, it is the second most recurrent type of cancer in women after nonmelanoma skin cancer (INCA, 2020). Despite the improvement in prevention, diagnosis, and classification methods, there is still a high mortality rate (Bray et al., 2018), which justifies the search for new prognostic markers, among which analysis of non-coding RNAs stand out.

LncRNAs are non-coding RNAs with more than 200 nucleotides in length, with essential regulatory roles in several biological processes and associated with many pathological conditions (Cipolla et al., 2018). There are more than 17,000 lncRNA genes described in the human genome (Frankish et al., 2019). Despite the large number of IncRNAs identified, many of them have unknown functions. Additionally, genomic variants, including single nucleotide polymorphisms (SNPs), may contribute to modifying the functioning of lncRNAs, thus affecting cancer susceptibility (Wapinski and Chang, 2011) but there are few studies focused on these regions, showing that this is still an underexplored field.

Located in the region of $A Q P 4-A S 1$, the SNP rs527616 $(\mathrm{C}>\mathrm{G})$, has been indicated by genome-wide association studies

Send correspondence to Jaqueline Carvalho de Oliveira. Universidade Federal do Paraná, Departamento de Genética, Av. Cel. Francisco H. dos Santos, 100, CEP 81530-000, Jardim das Américas, Curitiba, PR, Brazil. E-mail:jaqueline.carvalho@ufpr.br.
(GWAS) (Michailidou et al., 2017) as being associated with an increased risk of developing breast cancer, but this variation has not been deeply investigated.

The AQP4-AS1 gene (Aquaporin 4 antisense RNA 1) transcribes an antisense lncRNA of unknown function (Halladay et al., 2018). As many antisense transcripts may regulate the host transcript (Wight and Werner, 2013), the nearby aquaporin 4 gene $(A Q P 4)$ may help us to understand the role of this lncRNA.

AQP4 has a fundamental role in maintaining water homeostasis, which is believed to be associated with the development of tumors (Li et al., 2016). In breast cancer, AQP4 is low expressed in comparison to non-tumor tissues and associated with prognosis (Shi et al., 2011; Zhu et al., 2019).

By knowing the importance of AQP4 in breast cancer, we aimed to perform a case-control study to evaluate the association of the SNP rs527616 (C> G) with breast cancer susceptibility in a southern Brazilian population, and to further evaluate the $A Q P 4-A S 1$ expression in public data.

\section{Subjects and Methods}

\section{Study cohort}

The analyses were performed using tumor samples of 306 patients with sporadic breast cancer from the Hospital Nossa Senhora das Graças (HNSG), located in Curitiba, in the South of Brazil. As control group, we used peripheral 
blood samples of 312 women with no cancer history, from the biobank of the Department of Genetics at Federal University of Paraná (UFPR), Curitiba, Brazil.

Both groups (patients and controls) were from the same region in the south of Brazil, most living in the metropolitan region of Curitiba, Parana State. Ancestry information was obtained from self-reported patients' records, with $84.7 \%$ white, $10.7 \%$ black or brown, and $1.9 \%$ others.

Although genomic information to assess ancestry was not available for all individuals, previous studies showed that, in this Brazilian region and in accordance with phenotypic classification, the white population is of predominantly of European ancestry (more than $80 \%$ contribution) and the black/ brown population consists predominantly of African ( $\sim 50 \%)$ and European $(\sim 42 \%)$ ancestry, with a smaller contribution of Amerindian ( $\sim 8 \%)$ ancestry (Probst et al., 2000, BraunPrado et al., 2000).
A subset of patients, also included in the present study, was genotyped using a SNP chip Illumina Infinium QC Array (Illumina Inc., CA), which contains 15,949 markers (including $\sim 3,000$ ancestral informative markers (AIMs) and, based on the results previously shown, the genetic analysis was able to differentiate the two main population groups, European (EUR) and African (AFR) in our samples, thus confirming the self-report ethnicity information (Sugita et al., 2016).

The mean ages of the case and the control groups were $56.23 \pm 15$ and $47.66 \pm 4.69$. Histopathological parameters are summarized in Table 1. The immunohistochemical classification was based on Goldhirsch et al. (2013). The samples were collected under the approval of the Human Research Ethics Committee of the Health Sciences Sector of UFPR, under the number CAAE: 67029617.4.0000.0102. All participants signed an informed written consent.

Table 1 - Clinical and Histopathological Data of Breast Cancer patients.

\begin{tabular}{|c|c|c|c|c|c|}
\hline \multicolumn{6}{|l|}{ Breast cancer cases $n=306$} \\
\hline Histology & $\mathrm{n}$ & $\%$ & Tumor Grade & $\mathrm{n}$ & $\%$ \\
\hline Ductal & 209 & $68 \%$ & I & 22 & $7 \%$ \\
\hline Lobular & 30 & $10 \%$ & II & 115 & $38 \%$ \\
\hline Mucinous & 8 & $3 \%$ & III & 59 & $19 \%$ \\
\hline Mixed duct-lobular & 17 & $6 \%$ & Without information & 110 & $36 \%$ \\
\hline Others & 29 & $9 \%$ & & & \\
\hline Without information & 13 & $4 \%$ & & & \\
\hline Immunohistochemical Subtype & $\mathrm{n}$ & $\%$ & Lymph node metastasis & $\mathrm{n}$ & $\%$ \\
\hline Luminal A & 79 & $26 \%$ & Presence & 86 & $28 \%$ \\
\hline Luminal B & 132 & $43 \%$ & Absence & 176 & $58 \%$ \\
\hline HER2 positive & 17 & $6 \%$ & Without information & 44 & $14 \%$ \\
\hline Triple-negative & 29 & $9 \%$ & & & \\
\hline Without information & 49 & $16 \%$ & & & \\
\hline
\end{tabular}

\section{Genotyping}

DNA extraction was performed by the phenol-chloroform method in tissue samples. The peripheral blood DNA from women with no cancer was extracted by the salting-out method and used as control (Serino et al., 2019)

The SNP rs527616 genotyping was performed by PCR with specific sequence primers (PCR-SSP), using a set of specific primers for the recognition of each allele. Allele C: Forward 5'GCTCCAGTGCTATTTG3 'and Reverse 5'ACAGGTCAAGGAAATGC3', yielding a product with the size of $167 \mathrm{bp}$. Allele G: Forward 5 'GTTGTAGAAGGCACAGTTG3' and Reverse 5 'AGGACAAGTCTAAACTAGGG3', yielding a product with the size of $117 \mathrm{bp}$. PCRs were performed from $2 \mu \mathrm{l}$ of DNA in a concentration of $20 \mathrm{ng} / \mu \mathrm{l}$ and $160 \mathrm{pmol}$ of specific primer in the presence of Master Mix for conventional PCR (1x), containing $0.2 \mathrm{mM}$ dNTPs, $50 \mathrm{mM} \mathrm{KCl,} 10 \mathrm{mM}$ Tris$\mathrm{HCl}$ and 1.25 U Taq polymerase, developed by IBMP, ICC / FioCruz. The PCR conditions were: $95^{\circ} \mathrm{C}$ for $10 \mathrm{~min}$, followed by 35 cycles of $96{ }^{\circ} \mathrm{C}$ for $30 \mathrm{~s}, 60^{\circ} \mathrm{C}$ for $30 \mathrm{~s}, 72{ }^{\circ} \mathrm{C}$ for $30 \mathrm{~s}$ and ending with a cycle at $70^{\circ} \mathrm{C}$ for $10 \mathrm{~min}$. For each
PCR performed, a heterozygous sample with the confirmed genotype and a negative control were included with the aim to ensure that there were no contamination and genotyping errors. The results were interpreted after electrophoresis analysis on $2 \%$ agarose gel stained with Gel Red Biotium (Figure 1).

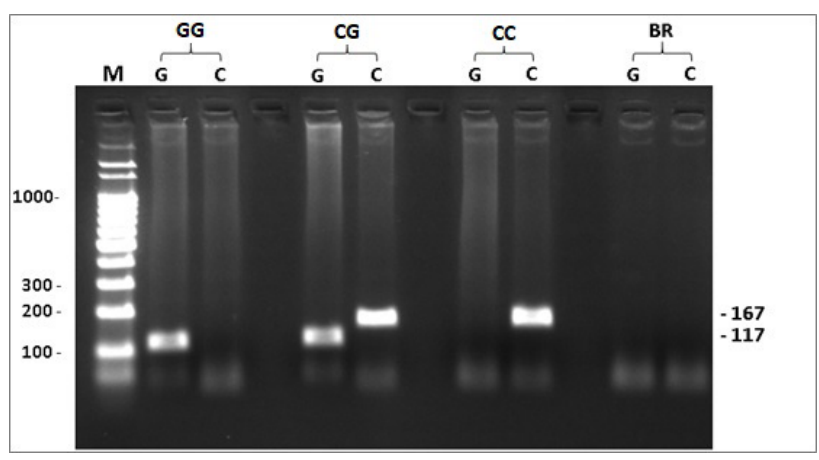

Figure 1 - Electrophoretic pattern of allele specific PCR of rs527616 $(\mathrm{C}>\mathrm{G})$, located in the lncRNA AQP4-AS1. M: Molecular weight marker, GG: Homozygous sample, CG: heterozygous sample, CC: homozygous sample, BR: white control. Expected fragment size: C-167 bp and G-117 bp. 
PCR-SSP method had high sensitivity and all individuals were genotyped. We validated the specificity and accuracy of our PCR-SSP method by sequencing samples containing the genotype homozygotes CC / GG and the heterozygotes CG with Sanger method.

\section{Statistical analysis}

By using the allele frequencies published by GWAS, we performed the sample size calculation, considering the $95 \%$ confidence interval and the prevalence of less frequent alleles in $20 \%$ of the population. We estimated the minimum sample size of 300 patients and 300 controls required for reliable production data (Beiguelman, 1988). For the genotypic frequency tests of the control and patient groups, we used the test of deviations in the proportions of the Hardy-Weinberg theorem by Chi-square. Additionally, we used the odds ratio (OR) calculation, as well as the Chi-Square test to assess whether the variables (breast cancer and SNPs) are independent.

Considering the overdominant model, we used FunModeling package to find the point (cut-off) with the most significant split according to age at diagnosis (44 years-old) and calculated the OR in both groups. Logistic regression was also used to confirm the role of the SNP in the overdominant model and age association.

Statistical analyses were performed with R software with the Nortest and readxl packages (Gross and Ligges, 2015; Wickham et al., 2019). For all tests described above, $\mathrm{P}$-values $<0.05$ were considered significant.

\section{Expression analysis in public data}

Expression analysis of $A Q P 4-A S 1$ in breast cancer was performed using the RNA-Seq data available from The Cancer Genome Atlas Program (TCGA) (Cancer Genome
Atlas Network). RNA-seq dataset, after normalization and logtransformation, were assessed by open-access web resource The Atlas of Noncoding RNAs in Cancer (TANRIC, https:// ibl.mdanderson.org/tanric/_design/basic/main.html).

We analyzed $A Q P 4-\bar{A} S 1$ expression level of $837 \mathrm{BC}$ patients, and 105 non-tumor tissue through Limma R package (Smyth et al., 2002) and GraphPad Prism8 using parametric $t$ test. We also compared the expression level of AQP4$A S 1$ according to the $\mathrm{BC}$ molecular classification, presence of receptors, disease stage, and tumor size. This analysis comprises 388 luminal A, 177 luminal B, 66 HER2-enriched, and 127 basal-like using ANOVA parametric test followed by Tukey test or $t$ test.

\section{Results}

\section{The presence of the CG genotype in rs527616 is associated with breast cancer risk}

From our genotyping results, we verified that the $\mathrm{C}$ allele is the least frequent one in both of the groups analyzed with minor allele frequency (MAF) of 0.30 in the patients' group and 0.29 in control group, with no statistical difference $(\mathrm{P}=$ 0.92). On the other hand, the genotype heterozygote $\mathrm{CG}$ is more frequent in the patients group, and the homozygotes $\mathrm{CC}$ and GG are more frequent in the control group.

Additionally, we calculated the OR for the recessive, dominant, and overdominant models (Table 2). The homozygotes are associated with lower risk and heterozygote, with a higher risk of $\mathrm{BC}$.

\section{Rs527616 is associated with age at diagnosis}

The SNP was significantly associated with age at the $\mathrm{BC}$ diagnosis. The risk genotype, $\mathrm{CG}$, is more frequent in older age group. The age stratification (age $\leq 44$ years and $>$

Table 2 - Genotype and allele frequencies of rs527616 in patients and controls.

\begin{tabular}{|c|c|c|c|c|}
\hline & Patients $(\mathrm{n}=306)$ & controls $(n=312)$ & & \\
\hline & n (\%) & n (\%) & $p$ & OR $95 \% \mathrm{CI}$ \\
\hline $\mathrm{CC}$ & $9(3 \%)$ & $25(8 \%)$ & 0.004 & $0.34(0.15-0.75)$ \\
\hline CG & $167(55 \%)$ & $129(41 \%)$ & 0.0009 & $1.7(1.23-2.34)$ \\
\hline GG & $130(42 \%)$ & $158(51 \%)$ & 0.035 & $0.71(0.52-0.98)$ \\
\hline \multicolumn{5}{|l|}{ Models } \\
\hline \multicolumn{5}{|l|}{ Dominant } \\
\hline GG & $130(42 \%)$ & $158(51 \%)$ & & \\
\hline $\mathrm{CG} / \mathrm{CC}$ & $176(58 \%)$ & $154(49 \%)$ & 0.04 & $1.38(1.01-1.90)$ \\
\hline \multicolumn{5}{|l|}{ Recessive } \\
\hline GG/CG & 297 (97\%) & $287(92 \%)$ & & \\
\hline $\mathrm{CC}$ & $9(3 \%)$ & $25(8 \%)$ & 0.004 & $0.34(0.15-0.75)$ \\
\hline \multicolumn{5}{|c|}{ Overdominant } \\
\hline CG & $167(55 \%)$ & $129(41 \%)$ & & \\
\hline $\mathrm{GG} / \mathrm{CC}$ & $139(45 \%)$ & $183(59 \%)$ & 0.0009 & $1.70(1.23-2.34)$ \\
\hline MAF (C) & $185(30 \%)$ & $179(29 \%)$ & 0,57 & $1,07(0.84-1.37)$ \\
\hline
\end{tabular}

$\mathrm{MAF}=$ minor allele frequency; $p=\mathrm{P}$-value; $\mathrm{OR}=$ odds ratio $95 \% \mathrm{CI}=95 \%$ confidence interval. Control group has no deviation in the proportions of the Hardy-Weinberg equilibrium. 
44 years) showed that the risk effect of the [CG] genotype of rs527616 was mainly in the older age group ( $>44$ years of age) with slightly more increased risk ([CG] vs. [CC, GG]: $\mathrm{OR}=1.89$ (1.33-2.67); $\mathrm{P}=0.0002$, Table 3$)$. In contrast, in the younger age group ( $\geq 44$ years of age), the genotype frequencies showed no significant association with BC.

The allele and the genotype frequency are not associated with clinical variables in the present study. We analyzed association with subtypes, including luminal and triple negative $(\mathrm{P}=0.14)$, histopathological parameters: invasion of regional lymph nodes $(\mathrm{P}=0.16)$, and degree of tumor differentiation $(\mathrm{P}=0.65)$.

\section{In silico gene expression analysis}

According to TCGA expression data, AQP4-AS1 is down-regulated in $\mathrm{BC}$ tissue compared to the non-tumoral counterpart (Figure 2A), and the molecular subtype luminal A has a high level of the lncRNA in comparison with the other subtypes (Figure 2B). Besides the molecular classification, we examined the expression of $A Q P 4-A S 1$, taking into consideration the mainly used immunohistochemical markers, tumor size, and disease stage (Figure 3).

$A Q P 4-A S 1$ is also highly expressed in groups of usual better prognosis, including HER 2 negative, stage 1 of disease, and smaller tumor size (T1). These results suggest that the low expression of AQP4-AS1 may be a common event in $\mathrm{BC}$, and the high expression is associated with a better prognosis.

\section{Discussion}

Growing evidence suggests that SNPs may have paramount importance in genetic susceptibility to breast cancer (Li et al., 2019), but SNPs in lncRNA loci are underexplored.
Michailidou and colleagues, in a GWAS, presented an association between breast cancer and the SNP rs527616 in European and East Asian ancestry population (Michailidou et al., 2013; Michailidou et al., 2017). In the present study, we searched for this association in a cohort from the South of Brazil, in a case-control study.

The minor allele frequencies (MAF) in the Brazilian control group is $\mathrm{C}=0.3$, similar to the global population frequency MAF=0.34 (Phan et al., 2020). The data released by GWAS showed an association between the risk of breast cancer and the allele $(\mathrm{G})(\mathrm{OR}=1.03, \mathrm{CI} 1.02-1.05, \mathrm{P}<0.001)$ (Michailidou et al., 2017).

The GWAS usually includes a massive number of samples and loci, but it does not deepen the evaluation of a specific locus. For example, in the rs527616 analysis, only allele frequency was compared, while the influence of genotypes on BC susceptibly was not assessed. On the other hand, herein, we emphasized the heterozygote genotype in $\mathrm{BC}$ risk association.

In the BC group, we observed a frequency above the expected for $\mathrm{CG}$ heterozygotes and below the expected for $\mathrm{CC}$ and GG homozygotes; but no allele association was found in our Brazilian cohort. Analyzing only allele frequency, Zhang et al. (2014), also did not find any BC association in Chinese women.

Our data suggest that $\mathrm{CC}$ is a protective genotype and that the heterozygote $\mathrm{CG}$ is associated with increased susceptibility to breast cancer, thus reinforcing the importance of evaluating the influence of genotypes. As to the genotype GG, although it is significant, the $95 \%$ confidence interval range is close to 1 , so it must be interpreted with caution.

Table 3 - Distribution of patients with genotypes CG and GG + CC in overdominant model based on age of diagnosis.

\begin{tabular}{|c|c|c|c|c|}
\hline & $\begin{array}{c}\leq 44 \text { years } \\
(n=58)\end{array}$ & $\begin{array}{l}\text { Controls } \\
(n=312)\end{array}$ & & \\
\hline & $\mathrm{n}(\%)$ & $\mathrm{n}(\%)$ & $p$ & OR 95\%CI \\
\hline $\mathrm{CC}$ & $2(3.5 \%)$ & $25(8.0 \%)$ & & \\
\hline $\mathrm{CG}$ & $25(43.1 \%)$ & $129(41.4 \%)$ & & \\
\hline GG & $31(53.4 \%)$ & $158(50.6 \%)$ & & \\
\hline \multicolumn{5}{|c|}{ Overdominant } \\
\hline $\mathrm{CG}$ & $25(43.1 \%)$ & $129(41.4 \%)$ & & \\
\hline $\mathrm{GG} / \mathrm{CC}$ & $33(56.9 \%)$ & $183(58.6 \%)$ & 1.07 & $0.93(0.60-1.89)$ \\
\hline \multicolumn{5}{|c|}{ Patients with $\leq 44$ years-old at diagnosis. } \\
\hline & $\begin{array}{c}>44 \text { years } \\
(\mathrm{n}=224)\end{array}$ & $\begin{array}{l}\text { Controls } \\
(n=312)\end{array}$ & & \\
\hline & $\mathrm{n}(\%)$ & $\mathrm{n}(\%)$ & $p$ & OR 95\%CI \\
\hline $\mathrm{CC}$ & $5(2.2 \%)$ & $25(8.0 \%)$ & & \\
\hline $\mathrm{CG}$ & $128(57.2 \%)$ & $129(41.4 \%)$ & & \\
\hline GG & $91(40.6 \%)$ & $158(50.6 \%)$ & & \\
\hline \multicolumn{5}{|c|}{ Overdominant } \\
\hline CG & $128(57.2 \%)$ & $129(41.4 \%)$ & & \\
\hline $\mathrm{GG} / \mathrm{CC}$ & $96(42.8 \%)$ & $183(58.6 \%)$ & 0.0002 & $1.89(1.33-2.67)$ \\
\hline
\end{tabular}

Patients with more than 44 years-old at diagnosis. 


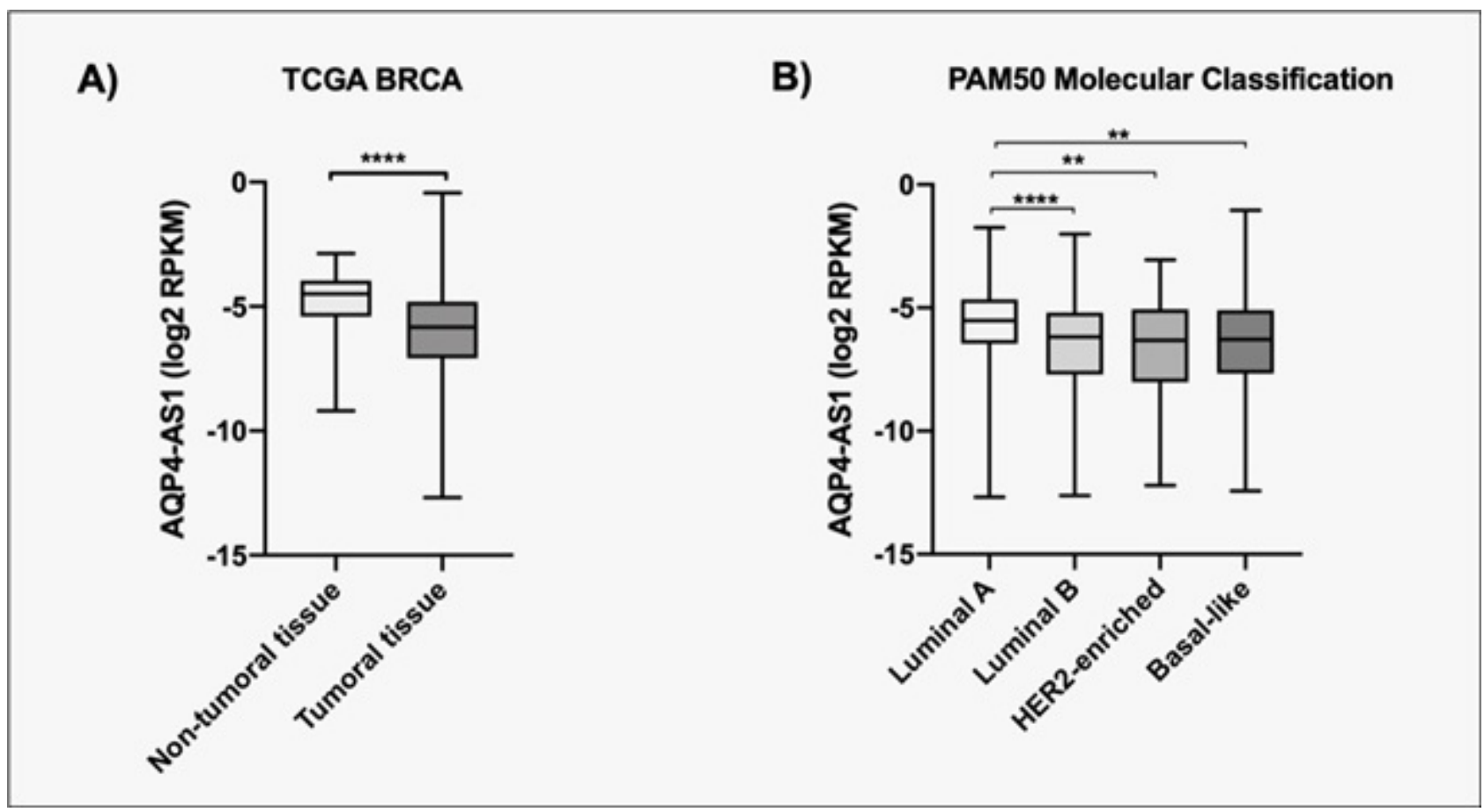

Figure 2 - Expression of AQP4-AS1 in TCGA data. A. Expression of $A Q P 4-A S 1$ in non-tumoral tissue and tumor. B. Expression of $A Q P 4-A S 1$ in different molecular subtypes of breast cancer. $* * \mathrm{p}<0.001 * * * \mathrm{p}<0.0004,{ }^{* * * *} \mathrm{p}<0.0001$.

A)

HER2 IHC Status

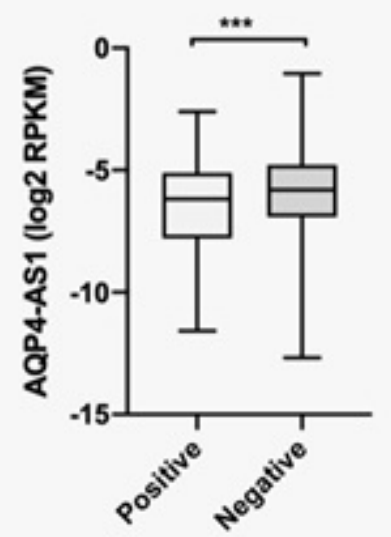

B)

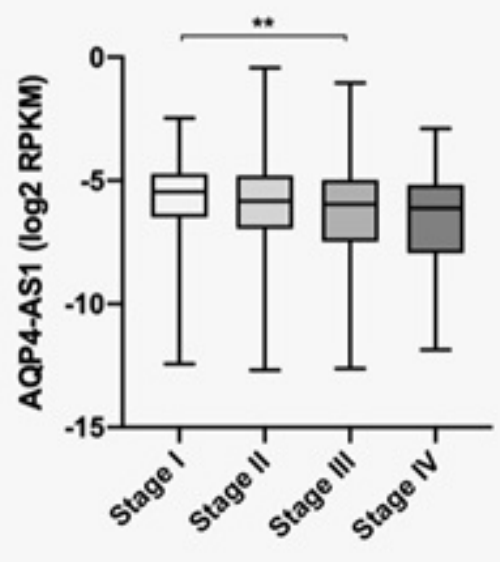

C)

Tumor size

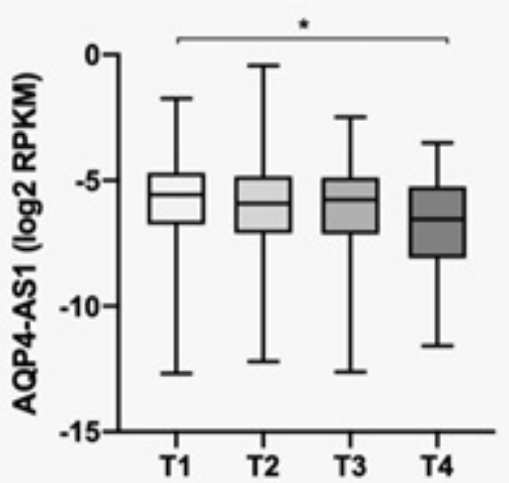

Figure 3 - Expression of $A Q P 4-A S 1$ according to immunohistochemical (IHC) markers, stage and size of tumor. A. Epidermal growth factor receptor 2 (HER2) status, B. Stage of disease and C. Size of Tumor, dates from TCGA RNA-seq data. * $\mathrm{p}<0.05, * * \mathrm{p}<0.001 * * * \mathrm{p}<0.0004$.

APQ4-AS1 lncRNA was not previously studied, and description about secondary structure, sites of interaction with other molecules and mechanisms of action are absent. Therefore, it is difficult to hypothesize the selective mechanism for the heterozygous genotype. However, bearing in mind that SNPs can change the structure of a lncRNA - and a secondary structure is essential for its role - in heterozygotes, both molecules are expressed simultaneously and this could amplify the possible interactions and also act differently in cell context. But further studies are essential for a better characterization of mechanism of action of this lncRNA.
A limitation of the present study is the absence of genomic information to assess ancestry for all individuals. We approached this issue including the self-reported patient records on ancestry. Considering the population analyzed, previous studies characterized the genetic background and, in accordance with self-phenotypic classification, this population is predominantly made up of European origin individuals (more than $80 \%$ of contribution).

The allele and genotype frequencies are not associated with clinical variables in the present study. This SNP was not associated with disease-free survival of triple-negative BC 
patients (Yuan et al., 2017), or with estrogen, HER-2 status, and BC subtypes (Zhang et al., 2014).

On the other hand, rs527616 was also associated with age, showing higher frequency of the CG risk genotype among older BC diagnosed patients. The heterogeneity of BC by age is well known, most notably for the high frequency of germinative mutations in younger patients and for the rising rates of hormone responsive subtypes and important lifestyle/ reproductive factors in older patients (Diab et al., 2000; Momenimovahed and Salehiniya, 2019). The risk genotype could be associated with a mechanism more involved in this group of patients, but further details in lncRNAs mechanism of action are important to help improve knowledge about this relation.

Older BC diagnosed patients are usually associated with better prognosis and, in expression analysis, higher expression of $A Q P 4-A S 1$ in patients were also associated with better outcome groups.

According to the expression data, there is a reduction in the expression of $A Q P 4-A S 1$ in the tumor tissue in comparison with the non-tumor tissue and the higher expression in luminal A subtype in comparison with the other subtypes. In addition, its expression was higher in patients in the first stage and minor tumor size, suggesting its relation with a better prognosis. $A Q P 4-A S 1$ expression was not previously analyzed in breast cancer, but the gene $A Q P 4$ expression has the same profile of the $A Q P 4-A S 1$, with low expression in tumor and the expression associated with better prognosis (Shi et al., 2011; Zhu et al., 2019).

Aquaporins (AQPs) are a family of small membrane transport proteins that act as selective pores for water and small solutes (Verkman et al., 2008; Mobasheri and Barrett-Jolley, 2013). More specifically, AQP4 has a fundamental role in maintaining water homeostasis and it can be associated with the development of cancer (Li et al., 2016).

In breast cancer, AQP4 had a low expression in comparison with non-tumor tissues, and the patients with the lowest expression level had poor survival (Shi et al., 2011; Zhu et al., 2019). Additionally, down-regulation of AQP4 inhibits proliferation, migration, and invasion in breast cancer cell lines (Li et al., 2016).

As many antisense lncRNAs act regulating the host gene, this may be a mechanism for the role of $A Q P 4-A S 1$. It is known that antisense genes can alter the expression of sense genes in several ways, such as DNA methylation, chromatin modification, variation of isoforms, and alteration of RNA stability (Pelechano and Steinmetz, 2013). However, further studies need to be carried out to elucidate the interactions of this lncRNA.

Additionally, the homozygote genotypes are less frequent in tumor samples, thus it would be interesting to check if SNPs genotypes are associated with different expression levels. The above suggestion is feasible since it is known that SNPs can interfere in the expression of a gene by changing the structure of a lncRNA, also on its binding site to proteins and secondary mechanisms of the corresponding messenger RNAs, or even by changing its interaction (Li et al., 2019).

Our results are relevant to emphasize the potential of the role of AQP4-AS1 lncRNAs role in breast cancer.
In conclusion, we describe for the first time in a Brazilian population that the rs527616 polymorphism $(\mathrm{C}>\mathrm{G})$ is associated with breast cancer susceptibility, with CG as the risk genotype and $\mathrm{CC}$ as the genotype with protective effect. Furthermore, AQP4-AS1 has low expression in BC samples and high expression groups of better prognoses: luminal A, HER2 negative, stage 1, and tumor size T1.

\section{Acknowledgments}

This research was in part supported by Coordenação de Aperfeiçoamento de Pessoal de Nível Superior (CAPESFinancial Code 001). Special thanks to the Immunogenetics and Histocompatibility Laboratory (LIGH) of the Federal University of Paraná for sharing their biobank and their physical structure. We thank Marc Breyer for assistance with English language editing.

\section{Conflict of interest}

We declare that there is no conflict of interest that could be perceived as prejudicial to the impartiality of the reported research.

\section{Authors Contributions}

RDM, CM, IJC and JCO conceived the study, RDM, CM, GAKR, DFG and JCO conducted and supervised the experiments; RDM, CM, EMSFR, RLRS, IJC and JCO analyzed the data, RDM, CM, EMSFR and JCO wrote the draft manuscript, RSL, CAU and FK collected the samples and revised all clinical data; all authors read and approved the final version.

\section{References}

Beiguelman B (1988) Curso Prático de Bioestatística. Sociedade Brasileira de Genética, Ribeirão Preto, SP, Brazil.

Braun-Prado K, Vieira Mion AL, Farah Pereira N, Culpi L and PetzlErler ML (2000) HLA class I polymorphism, as characterised by PCR-SSOP, in a Brazilian exogamic population. Tissue Antigens 56:417-427.

Bray F, Ferlay J, Soerjomataram I, Siegel RL, Torre LA and Jemal A (2018) Global cancer statistics 2018: GLOBOCAN estimates of incidence and mortality worldwide for 36 cancers in 185 countries. CA Cancer J Clin 68:394-424.

Cancer Genome Atlas Network (2012) Comprehensive molecular portraits of human breast tumours. Nature 490:61-70.

Cipolla GA, De Oliveira JC, Salviano-Silva A, Lobo-Alves S, Lemos DS, Oliveira LC, Jucoski TS, Mathias C, Pedroso GA, Zambalde EP et al.(2018) Long non-Coding RNAs in multifactorial diseases: Another layer of complexity. Noncoding RNA 4:13.

Diab SG, Elledge RM and Clark GM (2000) Tumor characteristics and clinical outcome of elderly women with breast cancer. J Natl Cancer Inst 92:550-556.

Frankish A, Diekhans M, Ferreira AM, Johnson R, Jungreis I, Loveland J, Mudge JM, Sisu C, Wright J, Armstrong J, et al. (2019) GENCODE reference annotation for the human and mouse genomes. Nucleic Acids Res 47:D766-D773.

Goldhirsch A, Winer EP, Coates AS, Gelber RD, Piccart-Gebhart M, Thürlimann B, Senn HJ, Albain KS, André F, Bergh J et al. (2013) Personalizing the treatment of women with early breast cancer: Highlights of the St. Gallen International Expert Consensus on the primary therapy of early breast Cancer 2013. Ann Oncol 24:2206-2223 
Halladay JR, Lenhart KC, Robasky K, Jones W, Homan WF, Cummings DM, Cené CW, Hinderliter AL, Miller CL, Donahue KE, et al. (2018) Applicability of precision medicine approaches to managing hypertension in rural populations. $\mathrm{J}$ Pers Med 8:16.

INCA - Instituto Nacional de Cancer José Alencar Gomes da Silva (2019) Estimativa 2020: incidência de câncer no Brasil. INCA, Rio de Janeiro.

Li J, Liu R, Tang S, Fend F, Wand X, Qi L, Liu C, Yao Y and Sun C (2019) The effect of long noncoding RNAs HOX transcript antisense intergenic RNA single-nucleotide polymorphisms on breast cancer, cervical cancer, and ovarian cancer susceptibility: A meta-analysis. J Cell Biochem 120:7056-7067.

Li YB, Sun SR and Han XH (2016) Down-regulation of AQP4 inhibits proliferation, migration and invasion of human breast cancer cells. Folia Biol (Praha) 62:131-137.

Michailidou K, Hal P, Gonzalez-Neira A, Ghoussaini M, Dennis J, Milne RL, Schmidt MF, Chang-Claude J, Bojesen SE, Bolla MK et al. (2013) Large-scale genotyping identifies 41 new loci associated with breast cancer risk. Nat Genet 45:353-361.

Michailidou K, Lindström S, Dennis J, Beesley J, Hui S, Kar S, Lemaçon A, Soucy P, Glubb D, Rostamianfar A et al. (2017) Association analysis identifies 65 new breast cancer risk loci. Nature 551:92-94.

Mobasheri A and Barrett-Jolley R (2013) Aquaporin water channels in the mammary gland: From physiology to pathophysiology and neoplasia. J Mammary Gland Biol Neoplasia 19:91-102.

Momenimovahed Z and Salehiniya H (2019) Epidemiological characteristics of and risk factors for breast cancer in the world. Breast Cancer 11:151-164.

Pelechano V and Steinmetz LM (2013) Gene regularion by antisense transcription. Nat Rev Genet 14:880-893.

Probst CM, Bompeixe EP, Pereira NF, de O Dalalio MM, Visentainer JE, Tsuneto LT and Petzl-Erler ML (2000) HLA polymorphism and evaluation of European, African, and Amerindian contribution to the white and mulatto populations from Paraná, Brazil. Hum Biol 72:597-617.

Serino L, Schultz T, Morais SB, Coelho CC, Cavalli LR, Cavalli IJ, Urban CA, Lima RS and Ribeiro EMSF (2019) Association of FOSL 1 copy number alteration and triple negative breast tumors. Genet Mol Biol 42:26-31.

Shi Z, Zhang T, Lou L, Zhao H, Cheng J, Xiang J and Zhao C (2011) Aquaporins in human breast cancer: identification and involvement in carcinogenesis of breast cancer. J Surg Oncol 206:267-272.

Sugita B, Gill M, Mahajan A, Duttargi A, Kirolikar S, Almeida R, Regis K, Oluwasanmi OL, Marchi F, Marian C et al. (2016)
Differentially expressed miRNAs in triple negative breast cancer between African-American and non-Hispanic white women. Oncotarget 7:79274-79291.

Verkman AS, Hara-Chikuma M and Papadopoulos MC (2008) Aquaporins-new players in cancer biology. J Mol Med (Berl) 86:523-529.

Wapinski $\mathrm{O}$ and Chang $\mathrm{H}$ (2011) Long noncoding RNAs and human disease. Trends Cell Biol 21:354-361.

Wight $\mathrm{M}$ and Werner A (2013) The functions of natural antisense transcripts. Essays Biochem 54:91-101.

Yuan J, Zhang N, Zhu H, Liu J, Xing H, Ma F and Yang M (2017) CHST9 rs1436904 Genetic variant contributes to prognosis of triple-negative breast cancer. Sci Rep 7:11802.

Zhang B, Li Y, Li L, Chen M, Zhang C, Zuo XB, Zhou FS, Liang B, Zhu J, Li P et al. (2014) Association study of susceptibility loci with specific breast cancer subtypes in Chinese women. Breast Cancer Res Treat 146:503-514.

Zhu L, Ma N, Wang B, Wand L, Zhou C, Yan Y, He J and Ren Y (2019) Significant prognostic values of aquaporin mRNA expression in breast cancer. Cancer Manag Res 11:1503-1515.

\section{Internet Resources}

Gross J and Liggs U (2015) Tests for Normality, http://www.cran.rproject.org/web/packages/nortest/nortest.pdf (accessed January 13, 2020)

Phan L, Jin Y, Zhang H, Qiang W, Shekhtman E, Shao D, Revoe D, Villamarin R, Ivanchenko E, Kimura M, et al. (2020) ALFA: Allele Frequency Aggregator. National Center for Biotechnology Information, U.S. NLM Gatew, http://www. ncbi.nlm.nih.gov/snp/docs/gsr/alfa/ (accessed 20 May 2019)

Smyth GK, Ritchie M, Thorne N, Wettenhall J, Shi W and Hu Y (2002) limma: Linear Models for Microarray and RNA-Seq Data User's Guide, https://chagall.med.cornell.edu/RNASEQcourse/ limma-usersguide-2018.pdf (accessed 05 February 2020)

Wickham H, Bryan J, RStudio, Kalicinski M, Valery K, Leitienne C, Colbert B, Hoerl D and Miller E (2019) Read Excel Files, Version 1.3.1, March 13, https://cran.r-project.org/web/ packages/readxl/index (accessed 15 January 2020)

Associate Editor: Mara Hutz

License information: This is an open-access article distributed under the terms of the Creative Commons Attribution License (type CC-BY), which permits unrestricted use, distribution and reproduction in any medium, provided the original article is properly cited. 